\title{
Genetic Data Concerning Shigella flexneri Serotypes 5 and 6
}

\author{
V. D. TIMAKOV, V. G. PETROVSKAYA, V. M. BONDARENKO, and N. A. KHOMENKO \\ Gamaleya Institute and Mechnikov's Institute of Vaccines and Sera, Moscow, USSR
}

It is shown that the genetic determinants of type-specific antigens I to $\mathrm{V}$ of Shigella flexneri controlling similar functions are localized near the lactosefermentation region on the chromosome; the determinant of antigen VI lies beyond it. The authors support the proposal that Shigella flexneri serotype 6 be excluded from Shigella flexneri and be considered as a subspecies in correspondence with the Soviet scheme of classification or even as a distinct species as Slopek and Mulczyk suggested. Genetic arguments based on the different behavior of $S$. flexneri strains in recombination with Escherichia coli $\mathrm{K}-\mathrm{I} 2 \mathrm{Hfr}$ are presented which support the division of $S$. flexneri serotype 5 into two subtypes, a and $b$, in correspondence with a similar division of other serotypes. The advisability of this division is confirmed by receptor analysis demonstrating differences in group-specific factors in strains of serotype 5 . The antigenic formula of subtype $5 \mathrm{~b}$ is $\mathrm{V}: 7 \ldots$ and of $5 \mathrm{a}, \mathrm{V}: 4 \ldots$

The genus Shigella is generally divided into four subgroups: $\mathrm{A}, S$. dysenteriae; $\mathrm{B}, S$. flexneri; C, S. boydii; and $\mathrm{D}, S$. sonnei. Subgroup B consists of six serotypes. Serotype 6 includes type Newcastle, strain boydii 88 , type Manchester, and some others.

In the Soviet scheme of classification, serotype 6 is considered to be a subspecies of $S$. flexneri (subspecies newcastle); in addition, serotype 5 is divided into two subtypes: $5 \mathrm{a}$ and $5 b(5)$.

A number of investigators $(2,12,18,22)$ have suggested excluding serotype 6 (type Newcastle) from $S$. flexneri and considering it as a subspecies or even a species of subgroup B on the basis of multiple differences in characteristics between serotype 6 and the other $S$. flexneri serotypes.

As to serotype 5, N. A. Khomenko (5) demonstrated the independent distribution in nature of strains of this serotype which carried different group-specific factors.

Nevertheless, the classification of Shigella flexneri has not changed up to now. In this communication, some genetic arguments are presented concerning the advisability of chang-. ing the classification of this organism.

\section{MATERIALS AND METHODS}

The strains of $S$. flexneri used in this study were obtained from the Mechnikov Institute of Vaccines and Sera (Moscow). All of the strains were typical in their biochemical characteristics and in their antigenic structure. As a rule, they required aspartic and nicotinic acids for growth on minimal medium. The donor strains of Escherichia coli $\mathrm{K}-12 \mathrm{Hfr} \mathrm{H}\left(\right.$ met $\left.^{-}\right)$ and K-12 Hfr $S_{160}\left(B_{1}^{-}\right)$were obtained from W. Hayes and A. T. Ganesan, respectively. Genetic crosses were performed as previously described (21). The presence of type- and group-specific antigens was determined by agglutination in single-factor sera produced by the Mechnikov Institute (Moscow).

\section{RESULTS AND DISCUSSION}

A summary of the published data concerning the salient differences between $S$. flexneri serotype 6 (type Newcastle) and the other serotypes of $S$. flexneri is presented in Table 1 .

As is evident from this table, strains of serotype 6 are strikingly different from those of the other serotypes. (i) Biochemical properties are as follows: existence of stable biotypes, higher fermentative activity, gas production by some strains on carbohydrate media, and nutritional requirements (special requirement in pantothenic acid) of serotype 6. (ii) Receptor function is as follows: strains of serotype 6 are less sensitive to colicins and phages than are strains of the other $S$. flexneri serotypes. (iii) Characteristics of the type-specific (main) antigen are: antigen VI is an antigen of type $K$, whereas antigens $I$ to $V$ are parts of somatic antigens. The immunochemical structure of serotype 6 is distinct from that of the other five serotypes. 


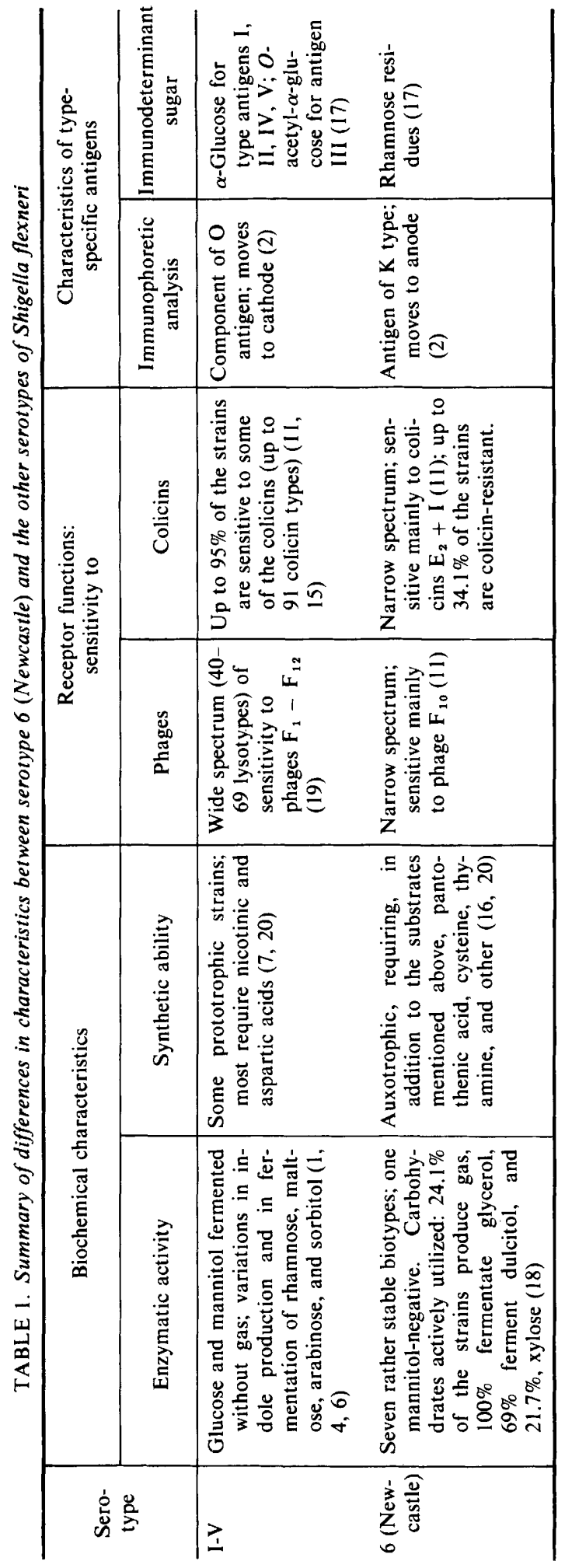


Studies of the genetic control of type-specific antigens in recombination between $S$. flexneri of different subtypes and $E$. coli $\mathrm{Hfr} \mathrm{C}$ showed the loss of some type-specific antigens by most of the hybrids acquiring the ability to utilize lactose $(8,14,21)$.

The results of the investigations carried out at our laboratory indicated some regularities in the behavior of type-specific antigens in recombination (21). An analysis of these data showed that, on the Shigella flexneri chromosome in the region adjacent to the lactose fermentation (lac) locus, there is a locus, which we call $\mathrm{Tp}$ (type), responsible for the synthesis of type-specific antigens I, II, IV, and V, but not of III and VI; we observed a high linkage rate (95 to 97\%) between the loss of the abovementioned antigens (I, II, IV, and V) and the acquirement of the lac marker, whereas, not a single lac hybrid of serotype 3 or 6 , produced from mating with $E$. coli $\mathrm{Hfr} \mathrm{C}$, had lost antigen III or VI, respectively.

It is important to emphasize that the results reported above paralleled the immunochemical characteristics of the type antigens. The immunodominant sugar of antigens I, II, IV, and $\mathrm{V}$ is the same, $\alpha$-glucose, III- $O$-acetyl- $\alpha$-glucose, and of antigen VI is rhamnosyl residues (17) (Table 1). Immunochemical studies of hybrids devoid of the antigens showed an absence of $\alpha$-glucose in their structure in comparison with the parent strains (9).

In our experiments, we observed a complicated behavior of type-specific antigens II and $\mathrm{V}$ in combination with group-specific factor 7,8 : in strains of serotype $2 b$, a simultaneous loss of both factors (II and 7,8) occurred, whereas $\mathrm{lac}^{+}$hybrids of serotype $5 \mathrm{~b}(\mathrm{~V}: 7,8)$ kept their antigens $\left(95 \% \mathrm{lac}^{+}\right.$hybrids of serotype $5 \mathrm{a}$ lost $\mathrm{V}$ antigen). Hence, the strains of serotype $5(\mathrm{~V}: 3,4)$ behaved differently, depending on the group-specific factor carried (21).

To prove the same localization of the determinant of antigen $\mathrm{V}$ in strains of $5 \mathrm{a}(\mathrm{V}$ : $3,4)$ and $5 b(V: 7,8)$, we carried out a cross between strain $5 \mathrm{~b}$ and $E$. coli $\mathrm{K}-12 \mathrm{Hfr} \mathrm{H}$, a strain more effective as a donor than $E$. coli $\mathrm{K}-12 \mathrm{Hfr}$ C.

The results of an analysis of the antigenic structures of $\mathrm{lac}^{+}$hybrids are presented in Table 2 .

It is evident from table 2 that most (96) of the $\mathrm{lac}^{+}$hybrids of strain $5 \mathrm{~b}$ in this cross, like the $\mathrm{lac}^{+}$hybrids of subtype $5 \mathrm{a}$, had lost type-specific antigen V. By analogy with serotype $2 b$, many (73) hybrids are devoid of two antigenic factors ( $\mathrm{V}$ and 7,8$)$ simultaneously.
However, with strain $5 \mathrm{~b}$, more complicated changes in antigenic structure were observed after recombination: the loss only of the $\mathrm{V}$ antigen (a transition into " $x$ " variant $[20$ strains] or into strains with formula $-: 3,4: 7,8$ [ 3 strains] ] and $1 \%$ cultures of "rough" hybrids were observed in previous crosses with $E$. coli $\mathrm{K}-12 \mathrm{Hfr} \mathrm{C}$ as well (21).

In our opinion, the previous observations mentioned above (21) and the data presented in this paper demonstrate differences in genetic behavior of five strains (serotypes $5 \mathrm{a}$ and $5 \mathrm{~b}$ ) in spite of the same localization of the determinants of antigen $\mathrm{V}$ in both cases. Apparently serotype 5 should be divided, on a genetic basis in to two subtypes ( $5 a$ and $5 b$ ).

For more detailed antigenic characteristics of these subtypes, an analysis of their groupspecific antigens was carried out by the method of agglutinin adsorption. In the first experiment, different portions of sera against strains of subtypes $2 a$ and $2 b$ were adsorbed with strains of subtypes $5 a$ and $5 b$ and with control strains of the " $y$ " and " $x$ " variants, respectively. These sera contained complexes of antibodies against the factors 3,4 and 7,8 .

The results showed that the control strains " $x$ " and " $y$ " completely adsorbed antibodies against antigens 7,8 and 3,4 respectively, whereas strains $5 b$ and $5 a$ did not adsorb

TABLE 2. Antigenic structure of lac ${ }^{+}$hybrids obtained from mating Shigella flexneri $5 b 186(V: 7,8)$ with Escherichia coli $\mathrm{K}-12 \mathrm{Hfr} \mathrm{H}^{a}$

\begin{tabular}{cccc}
$\begin{array}{c}\mathrm{N} \\
\text { hybrid } \\
\text { class }\end{array}$ & $\begin{array}{c}\text { No. of } \\
\text { hybrids }\end{array}$ & $\begin{array}{c}\text { Antigenic } \\
\text { structure }\end{array}$ & \multicolumn{1}{c}{ Comments } \\
\hline 1 & 73 & $-:(3,4)$ & $\begin{array}{c}\text { 67 Hybrids reacted } \\
\text { with serum } 3,4 ; \\
\text { 6 hybrids lost an } \\
\text { agglutinability by } \\
\text { sera V and } 7,8\end{array}$ \\
& & & \\
3 & 20 & $-: 7,8$ & \\
4 & 3 & $-: 3,4: 7,8$ & $\begin{array}{l}\text { V:7,8 } \\
?\end{array}$ \\
5 & 1 & $?$ & $\begin{array}{c}\text { Polyagglutinability, } \\
\text { trypaflavine (+) } \\
\text { reaction }\end{array}$ \\
\hline
\end{tabular}

${ }^{a}$ Mroz and Lachowicz (10) described a transition after recombination of a strain of subtype $5 b(V: 7,8,9)$ into the " $x$ " variant $(-: 7,8,9)$ in 50 of 50 lac hybrids studied. The insufficient number of the hybrids obtained and the use of serum with additional factor 9 make a comparison with our results difficult. However, there is a possibility of some deviation in individual behavior of the different strains of subtype $5 \mathrm{~b}$ in recombination. 
TABLE 3. Analysis of group-specific antigens of Shigella flexneri $5 b$ and $5 a$ by the method of agglutinin adsorption

\begin{tabular}{|c|c|c|c|c|c|c|}
\hline \multirow{2}{*}{$\begin{array}{l}\text { Sera against live } \\
\text { cultures of } \\
S . \text { flexneri }\end{array}$} & \multicolumn{6}{|c|}{ S. flexneri strains and their antigenic formulae (abbreviated) ${ }^{a}$} \\
\hline & $\begin{array}{c}2 b-1403 \\
\text { II }: 7,8\end{array}$ & $\begin{array}{c}5 b-545 \\
V: 7\end{array}$ & $\begin{array}{c}x-1340 \\
-: 7,8\end{array}$ & $\begin{array}{c}2 \mathrm{a}-1487 \\
\mathrm{II}: 3,4\end{array}$ & $\begin{array}{l}5 \mathrm{a}-249 \\
\mathrm{~V}: 3 ? 4 ?\end{array}$ & $\begin{array}{l}y-433 \\
-: 3,4\end{array}$ \\
\hline 2b Nonadsorbed & 25,600 & 12,800 & 25,600 & 128,000 & - & - \\
\hline $2 \mathrm{~b}$ Adsorbed with $5 \mathrm{~b}$ & 12,800 & 0 & 6,400 & - & - & - \\
\hline 2b Adsorbed with $x$-var & 12,800 & 0 & 0 & - & - & - \\
\hline $2 b$ Adsorbed with $2 b$ & 0 & 0 & 0 & - & - & - \\
\hline 2a Nonadsorbed & 51,200 & - & - & 102,400 & 12,800 & 51,200 \\
\hline 2a Adsorbed with 5 a & - & - & - & 25,600 & 0 & 1,600 \\
\hline 2a Adsorbed with $y$-var & - & - & - & 12,800 & 0 & 0 \\
\hline 2a Adsorbed with $2 \mathrm{a}$ & - & - & - & 0 & 0 & 0 \\
\hline
\end{tabular}

${ }^{a}$ Symbols: Titers in reciprocal index are shown; 0, absence of agglutination in dilution 1:100 and higher; -, not tested.

TABLE 4. Receptor analysis of group-specific antigens of Shigella flexneri 5 a in double-adsorbed serum

\begin{tabular}{|c|c|c|c|c|c|c|}
\hline \multirow{2}{*}{$\begin{array}{l}\text { Serum against live } \\
\text { culture of } \\
\text { S. flexneri } 2 \mathrm{a}\end{array}$} & \multicolumn{6}{|c|}{ S. flexneri strains and their antigenic formulae (abbreviated) ${ }^{a}$} \\
\hline & $\begin{array}{c}2 \mathrm{a}-1487 \\
\text { II }: 3,4\end{array}$ & $\begin{array}{l}y-433 \\
-: 3,4\end{array}$ & $\begin{array}{c}1 \mathrm{a}-1521 \\
\mathrm{I}: 4\end{array}$ & $\begin{array}{c}1 \mathrm{~b}-1478 \\
\mathrm{I}: 4,6\end{array}$ & $\begin{array}{l}5 a-249 \\
V: 3 ? 4 ?\end{array}$ & $\begin{array}{c}2 \mathrm{~b}-1403 \\
\mathrm{II}: 7,8\end{array}$ \\
\hline Nonadsorbed & 102,400 & 51,200 & 51,200 & 12,800 & 12,800 & 51,200 \\
\hline $\begin{array}{l}\text { Adsorbed with } 2 b \\
(\text { complex } 3,4)\end{array}$ & 25,600 & 6,400 & 6,400 & 6,400 & 1,60 & \\
\hline $\begin{array}{l}\text { Additionally ad sorbed } \\
\text { with 1a (factor } 3 \text { ) }\end{array}$ & 3,200 & 800 & 0 & 0 & 0 & 0 \\
\hline
\end{tabular}

${ }^{a}$ Symbols: As in Table 3.

antibodies (Table 3 ). This indicates that the set of antigenic factors in these strains is incomplete. As to subtype $5 b$, the results coincided with its known antigenic formula (V:7 ...).

However, the group-specific antigens of subtype 5 a have not yet been studied thoroughly. We therefore performed a double successive adsorption of serum $2 \mathrm{a}$ followed by an analysis of the remaining antibodies. At first, the serum was adsorbed with strain $2 b$ (portion I) and then additionally with 1 a (portion II). Both portions were studied in tube agglutination reactions with cultures possessing antigens 3,4 ( 2 a and variant "y") or antigenic factor 4 only (Ia, Ib) and with strain $5 \mathrm{a}$.

From the results presented in Table 4 , it is clear that, in the first portion of the adsorbed serum, all strains were agglutinated in high titers, including strain 5a $(1: 1600)$, as this serum contained complex antibodies 3,4 . In the second portion (lack of antibodies against factor 4), only the strains possessing antigen $3(2 \mathrm{a}, \mathrm{y}$-var) were agglutinated. Strains 1a,1 b, and 5 a did not react with it.
This experiment demonstrated that $S$. flexneri 5a lacks antigen 3. Hence, its formula should be designated as $\mathrm{V}:[4]$. . . Antigen 4 is placed in brackets to show the quantitative antigenic variations in subtype 5 a observed in these bacteria.

The division of serotype 5 into two subtypes and the correction of its antigenic formula should be useful in epidemiological analysis of dysentery outbreaks.

Further, we decided to ascertain the sites of the genetic determinants of type-specific antigens III and VI. As mentioned above, neither of the $\mathrm{lac}^{+}$hybrids of these serotypes in crosses with $E$. coli $\mathrm{K}-12 \mathrm{Hfr} \mathrm{C}$ lost the corresponding antigen (21).

Antigen III was shown (17) to be an acetylated form of antigen 7,8. This finding, together with our data, indicates that the 14 strains of serotype 3 studied by us are immune to the converting phage 7,8 responsible for the synthesis of this antigen $(3,13)$, suggesting therefore that phage 7,8 takes part in the synthesis of antigen III as well. 
TABLE 5. Characteristics of lac ${ }^{+}$hybrids of Shigella flexneri 1575 3a(III:6:7,8) obtained from crosses with Escherichia coli $\mathrm{K}-12$ Hfr strains

\begin{tabular}{c|c|c|c}
\hline \multirow{2}{*}{ Donor } & \multirow{2}{*}{ Expt } & \multicolumn{2}{|c}{$\begin{array}{c}\text { No. of lac }{ }^{+} \text {hybrids } \\
\text { with type III antigen }\end{array}$} \\
\cline { 3 - 4 } & & Lost & Retained \\
\hline E. coli K-12 & 1 & 28 & 60 \\
Hfr H & 2 & 31 & 49 \\
E. coli K-12 Hfr S 160 & 1 & 65 & 38 \\
\hline
\end{tabular}

TABLE 6. Characteristics of lac ${ }^{+}$hybrids of Shigella flexneri serotype $6(V I: 3,4)$ obtained from crosses with Escherichia coli $\mathrm{K}-12 \mathrm{Hfr}$ strains

\begin{tabular}{l|l|c|c}
\hline & \multicolumn{1}{|c|}{$\begin{array}{c}\text { Donor } \\
\text { E. coli } \\
\text { K-12 }\end{array}$} & \multicolumn{2}{|c}{$\begin{array}{c}\text { No. of lac hybrids } \\
\text { with type VI } \\
\text { antigen }\end{array}$} \\
\cline { 3 - 4 } Strain (biotype) & & Lost & Retained \\
\hline 1.1468 (Newcastle) & Hfr C & 0 & 150 \\
2.762 (Manchester) & Hfr C & 0 & 52 \\
3.673 (Boyd-88) & Hfr C & 0 & 22 \\
4.573 (Boyd-88) & Hfr C & 0 & 50 \\
$5.281 / 55$ (Boyd-88) & Hfr C & 0 & 100 \\
$6.281 / 55$ (Boyd-88) & Hfr H & 0 & 100 \\
$7.281 / 55$ (Boyd-88) & Hfr S 160 & 0 & 100 \\
\hline
\end{tabular}

Prophage 7,8 was shown to be attached to the site near the $\mathrm{Tp}$ locus, i.e., near the lac region $(13,14)$. To determine whether substitution of this region influences the production of antigen III, we crossed strain $S$. flexneri 1575 3a (III:6:7,8) with more active donor strains of E. coli $\mathrm{K}-12 \mathrm{Hfr} \mathrm{H}$ and $\mathrm{Hfr} \mathrm{S}_{160}$. It is evident that, in these crosses, some of the $l a c^{+}$hybrids lost the type III antigen (Table 5). Most of the hybrids lost an immunity to the converting phage 7,8 simultaneously. (More detailed data will be presented on this in a subsequent paper.)

In experiments with strains of serotype 6 of different biotypes and with different Hfr strains none of the $\mathrm{lac}^{+}$hybrids lost agglutinability with type VI serum (see Table 6).

Hence, in addition to multiple differences between the characteristics of $S$. flexneri serotype 6 and those of the other serotypes (mentioned in Table 1), new genetic data are presented which further differentiate serotype 6 from the others. In spite of the existence of peculiarities in the other $S$. flexneri serotypes, their determinants for type-specific antigens I, II, III, IV, and V are localized near the same region on the chromosome (21; Tables 2 and
$5)$, whereas the determinant of antigen VI is situated beyond this region (Table 6).

These data strongly support the conclusion of many investigators concerning the necessity for excluding serotype 6 from $S$. flexneri and for considering it as subspecies (in correspondence with the Soviet sheme of classification) or, as Slopek and Mulczyk (18) suggested, as a distinct species.

\section{ACKNOWLEDGMENTS}

We thank W. Hayes and A. Ganesan for kindly providing the Hfr strains of $E$. coli $\mathrm{K}-12$ used in this study.

\section{LITERATURE CITED}

1. Edwards, P. R., and W. H. Ewing. 1962. Identification of Enterobacteriaceae. Burgess Publishing Co., Minneapolis.

2. Gekker, V. D., E. D. Ravitch-Birger, and Y. A. Belaya. 1965. The position of Newcastle bacteria in the classification of the shigellae. Int. Bull. Bacteriol. Nomencl. Taxon. 15: 133-137.

3. Giammanco, G. 1968. Conversion lysogenique de caracters antigéniques de Shigella flexneri (antigene II de type et complexe 7,8 de grope). Ann. Inst. Pasteur 114: 63-76.

4. Kauffmann, F. 1959. Enterobacteriaceae. Moscow.

5. Khomenko, N. A. 1967. Serological varieties of Shigella flexneri serotype 5. Int. J. Syst. Bacteriol. 17: $53-55$

6. Khomenko, N. A., and B. S. Kiseleva. 1967. A study of fermentation characteristic of Sh. flexneri. Z. Microbiol. (Moscow) 2: 94-100.

7. Lachowicz, T., M. Mulczyk, and D. Popiel. 1963. Nutritional requirements of Shigella flexneri bacilli. Arch. Immunol. Ther. Exp. 11: 351 .

8. Luria, S. E., and J. W. Burrous. 1957. Hybridization between Escherichia coli and Shigella. J. Bacteriol. 74: 461-476.

9. Manson, R., D. A. R. Simmons, and B. G. Petrovskaya. 1970. Antigenic changes in Shigella flexneri following conjugation with Escherichia coli Hfr C. Eur. J. Biochem. 17: 472-476.

10. Mroz, E., and T. Lachowicz. 1970. Serologic changes in Shigella flexneri bacilli as a result of recombination with $\mathrm{E}$. coli $\mathrm{K}_{12}$. Arch. Immunol. Ther. Exp. 18: 353-356.

11. Mulczyk, M., S. Slopek, and H. Marcinowska. 1967. Phage typing, colicin sensitivity and colicinogeny of Shigella flexneri 6. Arch. Immunol. Ther. Exp. 15: 609.

12. Novgorodskaya, E. M. 1959. Certain consideration on the problem of dysentery bacilli classification. Z. Microbiol. (Moscow) 4: 9-13.

13. Petrovskaya V. G., and V. M. Bondarenko. 1969. Phage control of the group specific antigen 7,8 
synthesis in Shigella flexneri. Vestn. Akad. Med. Nauk SSR 12: 52-56.

14. Petrovskaya V. G., and V. M. Bondarenko. 1970. The genetic control of Shigella flexneri type and group antigens. Int. Congr. for Microbiol., Mexico, $1970,64$.

15. Piatrowski, K., and Y. Chomiczewski. 1968. Colicinogeny and colicin sensitivity of $S$. flexneri and $S$. sonnei strains. Arch. Immunol. Ther. Exp. 16: 295-303.

16. Schu, V., and E. Aldova. 1967. Vitamin $B_{1}$ and pantothenic acid as growth factors for Shigella flexneri. Zentralbl. Bakteriol. Parasitenk. Infektionskr. Orig. 204: 361.

17. Simmons, D. A. R. 1969. The immunochemistry of Shigella flexneri $\mathrm{O}$-antigen. The structure and biosynthesis of the $\mathrm{O}$-specific side chains of some representative serotypes. Eur. J. Biochem. 11: 554-575.
18. Slopek, S., and M. Mulczyk. 1967. Concerning the classification of Shigella flexneri 6 bacilli. Arch. Immunol. Ther. Exp. 15: 600 .

19. Slopek, S., M. Mulczyk, and A. Krukowska. 1968. Phage typing of Shigella flexneri. Arch. Immunol. Ther. Exp. 16: 512-519.

20. Timakov, V. D., V. G. Petrovskaya, V. M. Bond arenko, and T. A. Licheva. 1969. A study of the genetic control of the typespecificity synthesis in the subgroup B Shigellae antigens. Vestn. Akad. Med. Nauk SSR 11: 48-58.

21. Timakov, V. D., V. G. Petrovskaya, and V. M. Bondarenko. 1970. Studies on the genetic control of Shigella sub-group B type specific antigens. I. Behaviour of Shigella flexneri type specific antigens in sexual recombination of Shigella $\mathrm{x}$ E. coli. Ann. Inst. Pasteur 118(I): 3-9.

22. Troitsky, V. L. 1953. On classification of dysentery bacteriae. Z. Microbiol. (Moscow) 3: 7-11. 